\section{The Precambrian-Cambrian boundary and geochemical perturbations}

HsÜ et al. ${ }^{1}$ present intriguing data on geochemical perturbations in two Lower Cambrian sections in China. At or near the base of the lowest trilobite-bearing formations in Yunnan and the Yangtze Gorges, they found a clay layer containing $5 \%$ more negative $\delta^{13} \mathrm{C}$ and increased iridium, osmium, and gold contents relative to strata above and below the clay. A more negative $\delta^{18} \mathrm{O}$ perturbation was found a few centimetres upsection. Figures 1, 2 and 3 in ref. 1 show that the $\delta^{13} \mathrm{C}$, Ir, Os, and Au anomalies occur right at the China $\mathrm{C}$ marker while the text indicates that the anomalies occur above the marker. Hsü et al., using the China C marker as the Precambrian-Cambrian boundary (apparently using the palaeontological criterion of placing the boundary at the base of the formation with the lowestmost trilobite), concluded that the $\delta^{13} \mathrm{C}$ perturbation reflected a fertility crisis (due to a phytoplankton mass mortality or mass extinction brought about by a catastrophic event, hence the iridium anomaly) immediately preceeding the Cambrian explosion of invertebrate evolution.

Regardless of the precise position of the geochemical changes with respect to the China C marker, these data do not coincide with any measurable mass extinction or phytoplankton mass mortality, and do not precede the Cambrian explosion. They occur during the explosion, when Metazoa are undergoing the most magnificent radiation in their history.

The China $\mathrm{C}$ marker in Yunnan and the Yangtze Gorges, demarcates a lithologic boundary and the base of the lowest formation containing trilobites ${ }^{1}$. An unconformity has been reported at this boundary $^{2}$ although recent interpretations favour a facies change reflecting a transgression $^{3}$. Below China $\mathrm{C}$ and the horizons containing the geochemical anomalies, abundant and diverse pre-trilobite faunas are well known. In Yunnan at the Kunyang Phosphate Mine in strata older than the China $\mathrm{C}$ marker, some 74 invertebrate species have been noted ${ }^{3}$. There is general consensus among researchers on the Precambrian-Cambrian boundary, that it be placed at the lowest known appearance of diverse shelly fossils with a good potential for correlation ${ }^{4}$. In China, at Yunnan, this corresponds to the base of unit 7 of the Zhongyicun member ${ }^{4}$ (at China B). It must be noted that even below this datum, shelled invertebrates, albeit of comparatively low diversity, are found ${ }^{3}$. Similar faunal sequences and relationships are known from the Soviet Union, Mongolia, Mexico, Newfoundland, Spain, England, and elsewhere ${ }^{5}$. These pre-trilobite biotas, composed of millimetre-sized calcium carbonate and phosphatic shells (small shelly fossils), are so distinctive and widespread that the term Tommotian Stage is being used to encompass the strata containing them ${ }^{6}$. Phytoplankton represented by acritarchs, do not appear to suffer any mass mortality or extinction at or near the China $\mathrm{C}$ horizon; indeed, they underwent a radiation that parallels the animals ${ }^{7}$.

It is probable that the geochemical perturbations have nothing whatsoever to do with the first trilobites as suggested by Hsü et al. Trilobites, probably older than those known from Yunnan ${ }^{3}$ are found in Morocco, with Hupetina occurring below Lamdelella and Fallotaspis ${ }^{8}$. Unfortunately, the interregional correlation of earliest Cambrian trilobites is imprecise and does not agree with schemes based on archaeocyathids. Trace fossils like Rusophycus and Cruziana, attibutable to trilobites but more conservatively interpreted as having been produced by arthropods with sclerotized legs that behaved like trilobites, are known from strata older than China $C^{3,9}$. It is unnecessary to invoke the geochemical perturbations as an external, environmental stimulus for the early evolution of shelled animals. Evolutionary theory is consistent with the occurrence of a broad diversification in a world of unfilled or partially filled niches ${ }^{10}$.

An iridium spike has also been reported from the USSR's stratotype for the Precambrian-Cambrian boundary. The base of bed 8 (Pestrotsvet Formation) at Ulakhan-Sulugur, Siberia, contains a 6-fold iridium enrichment, but no anomalous trace element shifts (Os and Au not reported $)^{11}$. No $\delta^{13} \mathrm{O}$ and $\delta^{18} \mathrm{O}$ data were noted. The base of bed 8 , which rests with slight erosional unconformity on bed 7 , is roughly correlated on palaeontological grounds with unit 7 of the Zhongyicun ${ }^{11}$ or China B. However, iridium analyses of the same bed 8 samples by Orth et al. ${ }^{12}$ (and C. J. Orth, personal communication) failed to detect iridium enrichment.

Some entirely different conclusions can be drawn from Hsü et al. (1) iridium spikes are more common in the geological record than previously thought and some, possibly most, are not associated with mass extinctions; (2) other geochemical perturbations $\left(\delta^{13} \mathrm{C}, \delta^{18} \mathrm{O}, \mathrm{Os}, \mathrm{Au}\right)$ hitherto associated with iridium and catastrophies also occur without catastrophic effects on biota; (3) $\delta{ }^{13} \mathrm{C}$ excursions appear to have been common in the Vendian and early Cambrian (A. H. Knoll, personal communication). These might represent the response of the oceans to changes brought about by widespread biomineralization and the rapid diversification and proliferation of phytoplankters; and (4) geochemical perturbations across the Pre-
cambrian-Cambrian transition may be associated with small-scale stratigraphic breaks and could be used as a tool in recognizing such hiatuses. As suggested by Hsü $e t$ al., these geochemical perturbations may be useful as chemochronostratigraphic signals for the correlation of widely separated regions; but they may not necessarily be coincidental with biostratigraphic boundaries.

This work was supported by NSF grants EAR82-05809 and 85-08984.

\section{STANLEY M. AWRAMIK} Department of Geological Sciences Preston Cloud Research Laboratory, University of California,

\section{Santa Barbara}

California 93106, USA

1. Hsü, K. J., Oberhänsli, H., Gao, J. Y., Sun Shu, Chen Haihong \& Krähenbuhl, U. Nature 316, 809 (1985)

2. Liu Hung-Yun, Sha Ching-An \& Hu Shih-Ling Sci. Sin. 16, 266 (1973).

3. Luo Huilin et at. Sinian-Cambrian Boundary Stratotype Section at Meishucun, Jinning, Yunnan, China (People's Publishing House, Yunnan, 1984).

4. Cowie, J. W. Episodes 8, 93 (1985)

5. Rozanov, A. Yu. et al. Lower Cambrian Stage Subdivision, Stratigraphy (Acad. Sci. USSR, Nauka, 1984.)

6. Bengston, S. Lethaia 14, 372 (1981).

7. Vidal, G. \& Knoll, A. H. Nature 297, 57-60 (1982).

8. Szduy, K. Geol. Mag. 115, 83 (1978).

9. Glaessner, M. F. The Dawn of Animal Life (Cambridge University Press, New York, 1984)

10. Valentine, J. W. in Phanerozoic Life, Patterns and Process (eds Raup, D. M. \& Jablonski, D.) (Springer, Berlin, in the press).

11. Nazarov, M. A., Barsukova, L. D., Kolesov, B. M. \& Alekseev, A. S. Lunar planet. Sci. 14, 546 (1983).

12. Orth, C. J., Gilmore, J. S. \& Knight, J. D. Lunar planet. Sci. 16, 631 (1985)

THE paper by Hsü et $a l^{1}$ reporting geochemical anomalies, specifically with regard to $\delta^{13} \mathrm{C}$ and an iridium spike, near the base of the Cambrian in China commands attention. There have already been hints of major negative shifts in carbon isotope values near the PrecambrianCambrian transition ${ }^{2}$; the data in ref. 1 indeed may point to a dramatically changing oceanic productivity. Extraterrestrial agencies are often invoked as an explanation of iridium anomalies ${ }^{3}$, an option apparently followed by Hsü et al., but such an enrichment pattern in a black shale which appears to have been deposited in anoxic or dysaerobic conditions ${ }^{4}$ may also be of mundane origin.

The principal point we wish to take issue with, however, is the vigorously argued connection between these geochemical anomalies and the "Cambrian explosion". There are many triggering mechanisms that have been invoked to explain this dramatic evolutionary radiation of metazoans near the beginning of the Cambrian (the "cropping hypothesis" referred to by Hsü et al. being only one of them), but Hsü et al.'s proposal is the only one we know of that would place the triggering event well after the "explosion". The current major disagreements with regard to the global correlation of the Chinese Precambrian-Cambrian boundary sections 